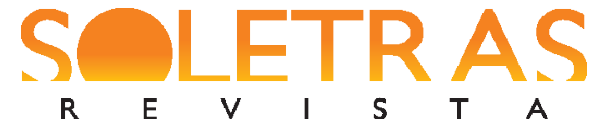

\section{Réquiem para Gerstäcker, o inquieto solitário}

Claudia Fernanda Pavan ${ }^{1}$

Gerson Roberto Neumann ${ }^{2}$

Resumo: Friedrich Gerstäcker foi um viajante e escritor alemão. Nasceu em Hamburgo em 1816 e dedicou sua vida a explorar as colônias do novo mundo, escrevendo diversas obras com foco principal na imigração alemã durante o século XIX e nas consequências desse movimento para o povo alemão. Antes de iniciar sua carreira como escritor, Gerstäcker viajou pelas Américas e por diversos outros países, conheceu de perto a vida dos imigrantes e viu na sua escrita uma forma de colaborar para a divulgação de informações acerca das questões envolvidas no processo de imigração. A coletânea de suas obras compreende mais de quarenta volumes; somente sobre a imigração alemã no Brasil, escreveu três obras ī todas publicadas na Alemanha na década de sessenta do século XIX. Contudo, só muito recentemente uma dessas obras foi traduzida para o português e publicada no Brasil. Neste trabalho, pretendemos destacar a importância desse autor dentro do polissistema literário brasileiro e discutir os motivos e as possíveis consequências do seu esquecimento.

Palavras-chave: Friedrich Gerstäcker. Migração no século XIX. Literatura traduzida.

\title{
Introdução
}

Ainda que a questão áutores canônicos x autores esquecidosô não represente uma discussão recente, ela certamente continua sendo necessária. No Brasil, é abordada por diversos autores, sob os mais variados ângulos (COUTINHO, 1996; PERRONE-MOISÉS, 1998; ALEXANDER, 2010, entre outros). Segundo Pausch (1991), quando nos perguntamos sobre autores esquecidos, estamos nos referindo, na verdade, à parte encoberta do iceberg $\bar{\imath}$ aquela infinitamente maior, que fica sob a água, ou seja, estamos nos referindo a um número sem fim de autores. Os que não foram totalmente esquecidos representam apenas a ponta do iceberg e alguns destes compõem, então, o que chamamos de cânone literário: um grupo de obras consideradas modelo ou, nas palavras de Alexander (2010, p. 124), ñuma coleção de textos consagradosò.

O mecanismo de composição do cânone literário é bastante controverso e isso faz parte imanente de sua natureza, posto que

\footnotetext{
${ }^{1}$ Mestranda do Programa de Pós-graduação em Estudos de Literatura, linha de Teoria, Crítica e Comparatismo, da UFRGS, RS, Brasil. E-mail: cp4v4n@gmail.com.

${ }^{2}$ Doutor em Ciências da Literatura pela FU-Berlin (2004). E-mails: gerson.neumann@gmail.com.
} 
[...] todos e quaisquer cânones são excludentes por natureza, visto que denotam sempre uma eleição do que pode e deve fazer veicular uma ñverdadeò, seja ela divina, estética, literária ou legal. Retomando Foucault, o cânone literário funcionaria como um disciplinador dos diversos discursos autodeclarados estéticos, mas que por diversas razões tornar-se-ão excêntricos, marginais e/ou periféricos, procurando responder aprioristicamente à demanda ño que é literatura?ò (INÁCIO apud ALMEIDA, 2014, p. 214).

A composição do cânone, segundo Bonnici (2007), é preconceituosa e unilateral, já que ño cânone literário ocidental é composto principalmente de obras escritas por autores brancos, masculinos e que pertencem às nações hegemônicas. As exceções são raras e provam a regraò (BONNICI, 2007, p. 38). Assim, por muito tempo ficaram excluídos do cânone grupos de escritores marginalizados e ainda hoje pouco representados: mulheres, negros, homossexuais, entre outros. Corrêa (1995) ressalta que o cânone ñreflete características positivas reguladoras de um comportamento compatível com a sociedade em questãoò (CORRÊA, 1995, p. 325, grifos nossos). Dessa forma, um comportamento não compatível mostra-se como característica de exclusão, o que provavelmente nada tem a ver com os aspectos estéticos e textuais de uma obra.

O conceito de cânone, portanto, encerra em si questões históricas e contextuais de relação com o controle e o poder que vão muito além de valores unicamente estéticos e textuais e envolvem aspectos relacionados à constituição de identidades nacionais, algo especialmente marcante no século XIX, período no qual o nacionalismo floresce intensamente. Nesse período, como lembra Alexander (2010), a literatura passou a assumir obrigatoriamente as cores nacionais: somente a literatura autóctone tinha valor real. Essa é, contudo, uma visão infecunda e ilusória. Infecunda, porque limita o conhecimento e apreciação de outras literaturas; ilusória porque, como aponta Anderson (2013), a nação é uma comunidade imaginada, um conceito arbitrário de comunhão entre pessoas que nunca chegarão a se conhecer, ñconcebida como uma profunda camaradagem horizontalò, apesar ñda desigualdade e da exploração efetivas que possam existir dentro delaò (ANDERSON, 2013, p. $34)$.

A questão da identidade nacional no século XIX mostra-se, portanto, bastante relevante, tanto para o Brasil quanto para a Alemanha. O Brasil tornou-se independente em 1822, e, mesmo que a unificação da Alemanha só tenha se dado em 1871, o sentimento nacionalista alemão tem suas origens no século XVI, com a Reforma Protestante iniciada por 
Martinho Lutero. Com o passar do tempo, esse sentimento foi crescendo, tornando-se cada vez mais forte, atingindo seu ponto mais alto no século XIX $\bar{i}$ século da formação dos estados nacionais (NEUMANN; PAVAN, 2015).

\section{Friedrich Gerstäcker ī Contexto e importância}

Mesmo sendo branco, homem e alemão ī ainda que, como vimos, a Alemanha só passe a existir como hegemonia política a partir de 1871 i Friedrich Gerstäcker, o autor que apresentamos a seguir, jamais fez parte dessa lista de nomes grandiosos. Ele sequer conseguiu se manter à deriva, afundou e foi esquecido junto com tantos outros escritores que compõem a base do iceberg literário ocidental.

Embora se trate de um escritor alemão, a importância de Gerstäcker para o polissistema literário brasileiro, quando consideramos o contexto de sua produção literária, é indiscutível. O século XIX é marcado já desde as primeiras décadas pela emancipação política do Brasil, o que desencadeou uma política de substituição da mão de obra escrava pela mão de obra imigrante. Trespach, no artigo Alemães para toda obra (2014), apresenta-nos uma visão resumida da situação em que se encontrava o Brasil naquele momento:

[p]elo Tratado de Aliança e Amizade, assinado logo depois com a Inglaterra, D. João havia se comprometido com a extinção gradual do tráfico negreiro até a sua proibição. O perigo de uma revolta de escravos, como a que havia libertado o Haiti de mãos francesas em 1791, era visto pela população branca e livre como algo iminente. Um pouco mais tarde, em carta ao imperador austríaco, sogro do príncipe D. Pedro (futuro D. Pedro I), o rei português expôs seu objetivo quanto ao projeto de mudar a fonte da mão de obra no Brasil: decidira ñsubstituir por colonos brancos os escravos negrosò. Do medo das revoltas escravas, da exigência externa pelo fim da escravidão e da necessidade de criação do minifúndio e da produção artesanal surgiu a política de imigração e colonização com alemães (TRESPACH, 2014, s. p.).

Nos estados alemães, nesse mesmo período, a situação econômica e política era devastadora. As guerras napoleônicas e a revolução de 1848, entre outras, contribuíram para aumentar a fome e a miséria dos diversos povos daquela região: westfalianos, pomeranos, bávaros, prussianos (FLORES apud NEUNFELD, 2016). Esse quadro trágico levou muitos alemães a colocar suas esperanças de uma vida melhor na emigração para o Brasil, sentimento que foi fortalecido pelas propagandas que visavam ao recrutamento de imigrantes para 


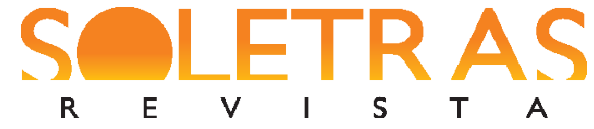

DOSSIÊ ï N. 34 ï 2017.2 ï CLAUDIA FERNHANDA PAVAN E GERSON ROBERTO NEUMANN

colonizar o território brasileiro e que alimentavam as expectativas e as fantasias dessas pobres pessoas.

Em 1822, coube a Georg Anton von Schaeffer $\ddot{i}$ amigo da princesa Leopoldina $\ddot{i}$ a missão de visitar as principais cortes alemãs em busca de colonos:

[a] proposta levada aos alemães pelo agente brasileiro era atraente. Para aqueles que quisessem fugir das guerras, do excedente populacional e da miséria na Europa, von Schaeffer oferecia 77 hectares de terra, isenção de impostos por 10 anos, animais de criação e sementes, além de outros subsídios (TRESPACH, 2014, s.p.).

Contudo, a realidade que aguardava aqueles que se lançavam a essa aventura era muitas vezes chocante, bem diferente daquilo que sonhavam. Duas das obras que Gerstäcker produziu com foco na temática da imigração alemã no Brasil ī A Colônia. Cenas da Vida no Brasil $^{3}$ e Um Contrato de Parceira. Conto para advertência e instrução de emigrantes e seus acompanhantes ${ }^{4} \overline{\mathrm{I}}$ tinham exatamente a finalidade de descrever o território brasileiro, apontar as vantagens da emigração, mas também alertar seus conterrâneos sobre as armadilhas do longo caminho percorrido até a chegada ao país e sobre o que os esperava a partir de então.

Considerado pela Assembleia Nacional de Frankfurt (Frankfurter Nationalversammlung) como perito em emigração, Gerstäcker recebeu da instituição mil táleres para visitar colônias alemãs além-mar e investigar possíveis localizações para novos assentamentos (GRABBE, 1997). É este engajamento político de Gerstäcker em relação às questões referentes à emigração o principal motivo da terceira viagem que ele realiza pela América do Sul a partir de 1860. Através do seu envolvimento nesses assuntos, ele tem a oportunidade de servir como intermediador entre o governo brasileiro, junto ao imperador Dom Pedro II, e as organizações promovedoras da emigração. Ele profere, então, no dia 21 de setembro de 1861, no Salão da Real Academia Militar, uma palestra a interessados em promover a vinda de alemães ao Brasil. No mesmo ano, o conteúdo da palestra é publicado pela Editora de Lorenz Winter sob o título: Die Deutschen im Ausland. Vorlesung gehalten von Friedrich Gerstäcker im Saale der Kaiserlichen Militär-Academie zu Rio de Janeiro, den 21. September 1861 [Os alemães no exterior. Palestra apresentada por Friedrich Gerstäcker no

\footnotetext{
${ }^{3}$ Título original: Die Colonie. Brasilianisches Lebensbild. Essa obra foi traduzida para o português e publicada pela Gradiva Editorial em 2016.

${ }^{4}$ Título original: Die Parcerie Vertrag. Erzählung zur Warnung und Belehrung für Auswanderer und ihre Freunde.
} 
Salão da Real Academia Militar no dia 21 de setembro de 1861] (NEUMANN; PAVAN, 2015, p. 2).

\section{Friedrich Gerstäcker ī Autor e obra}

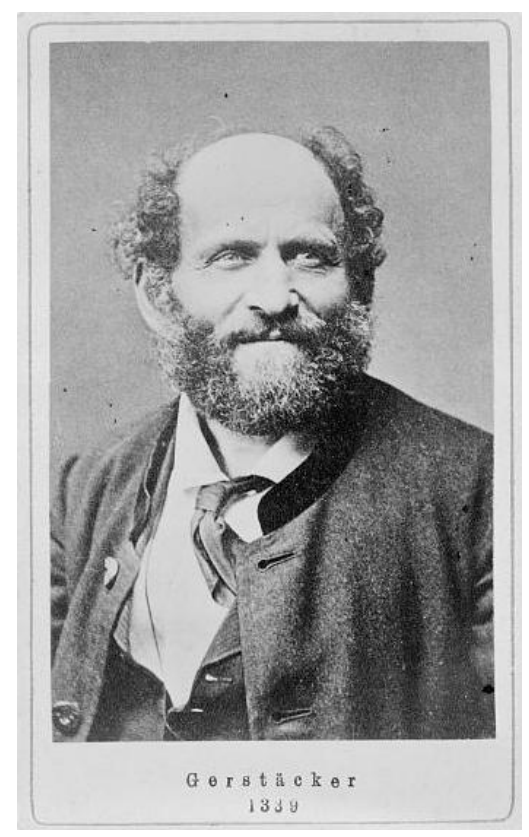

Fig. 1: Friedrich Gerstäcker Fonte: Library of Congress ${ }^{5}$

Friedrich Gerstäcker nasce em Hamburgo em 1816, em uma família de artistas: seu pai, Friedrich Samuel Gerstäcker, é um famoso cantor de ópera e sua mãe, Louise Friederike Gerstäcker (nascida Herz), atriz. Na época de seu nascimento, os dois trabalham no Teatro de Hamburgo. O pequeno Friedrich habitua-se às constantes viagens que a família faz desde bem cedo. Quando seu pai morre, em 1825, em decorrência da tuberculose, Gerstäcker tinha apenas nove anos. Sua mãe não tem condições de sustentar a família e deixa Friedrich e sua irmã, Molly, aos cuidados de Eduard Schütz, o tio que trabalhava como ator em Braunschweig.

Não surpreende, portanto, que aos 17 anos, Gerstäcker tenha decidido abandonar o curso de administração ī que iniciara contra sua vontade $\bar{\imath}$ e viaje a pé até Leipzig para confidenciar à sua mãe o desejo de emigrar para os EUA. Ela ainda consegue persuadi-lo a fazer um curso técnico agrícola a fim de se preparar para a vida nas colônias americanas e só

\footnotetext{
${ }^{5}$ Disponível em: http://www.loc.gov/pictures/resource/cph.3c34007/. Acesso em out. 2017. 


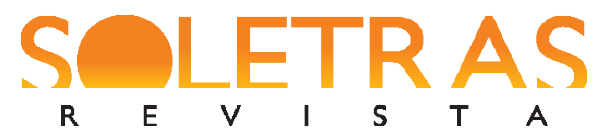

DOSSIÊ ï N. 34 i 2017.2 ï CLAUDIA FERNHANDA PAVAN E GERSON ROBERTO NEUMANN

alguns anos mais tarde, aos 21 anos, Gerstäcker faz sua primeira viagem para os EUA. Por seis anos, então, ele atravessa todo o continente norte-americano e, para sustentar-se, assume várias profissões pelo caminho: agricultor, lenhador, ferreiro e por algum tempo trabalha até como fogueiro em um barco a vapor no Mississipi.

Contudo, dono de um espírito inquieto e aventureiro, Gerstäcker não consegue se estabelecer em um único lugar. A Alemanha e o mundo tornaram-se pequenos demais para ele e, assim, Gerstäcker inicia uma vida cheia de aventuras, viajando pelas Américas e por diversos outros países, munido de seu material de escrita e de sua liberdade e seguindo o rastro da história feita pelos colonizadores alemães no século XIX: ño que eu poderia fazer na Alemanha? Numa vida regrada e, especialmente, numa vida dependente, eu não me encaixava maisò(GERSTÄCKER apud KÄTHER, 2012, s.p.). ${ }^{6}$

Sua vida é marcada pela inquietude e pela sede de exploração. Embora ele não tivesse o desejo expresso de se tornar escritor, vários fatores conspiraram para que ele abraçasse esse ofício. Seu primeiro livro, Streif- und Jagdzüge durch die Vereinigten Staaten Nordamerikas [Expedições de descoberta e caça pelos Estados Unidos da América do Norte], foi uma compilação das cartas que enviou à sua mãe durante os seis anos de sua primeira viagem pelos EUA. Segundo Hühnerfeld (2012/1957), ela percebeu algo incomum nas cartas do filho: um raro poder de observação, distanciamento e descrição que conferia àquela correspondência um caráter singular. Seguindo essa intuição, Louise Friederike Gerstäcker se empenha em publicar os escritos do filho, o que se dá em 1843. Ao retornar à Alemanha neste mesmo ano, Gerstäcker é surpreendido pela novidade e inicia, aí, sua carreira de escritor.

Essa primeira publicação é logo seguida por dois romances de aventura de grande sucesso junto ao público alemão, fascinado pelas histórias que desvelavam o novo mundo e o destino dos emigrantes alemães: Die Regulatoren in Arkansas [Os Justiceiros do Arkansas] (1846) e Die Flußpiraten des Mississippi [Os Piratas do Rio Mississipi] (1848). Em Die Regulatoren in Arkansas, Gerstäcker narra a vida dos colonos alemães no Arkansas e os feitos destes como justiceiros, que se defendiam do roubo de cavalos e de outras iniquidades fazendo justiça com as próprias mãos. Segundo Bittner (2016), na primeira metade do século XIX, uniões de justiceiros eram bastante comuns no oeste americano, especialmente depois

\footnotetext{
${ }^{6}$ Do alemão: "Was hätte ich auch in Deutschland gesollt? In ein geregeltes und besonders in ein abhängiges Leben paßte ich nicht mehr hinein.ñ
} 


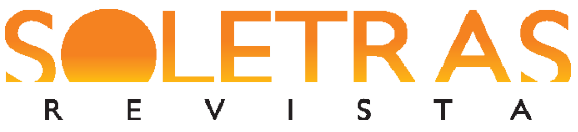

DOSSIÊ ï N. 34 ï 2017.2 ï CLAUDIA FERNHANDA PAVAN E GERSON ROBERTO NEUMANN

que a pena de morte pelo roubo de cavalos foi revogada em 1839. No prefácio dessa obra, Gerstäcker afirma:

[a] maior parte dos acontecimentos não foi, de forma alguma, inventada, mas de fato aconteceu $\mathfrak{C}$ mesmo que em outros lugares e durante um período maior de tempo. Ressalto, especialmente, que o pastor metodista remete a uma figura histórica (GERSTÄCKER, 1846, p. 02 ī tradução nossa) ${ }^{7}$.

Die Flusspiraten des Mississippi, publicado em 1848, é praticamente uma continuação do livro anterior: trata-se de um bando de piratas que se esconde em uma ilha do rio Mississipi, próxima à pequena cidade de Helena. No enredo, da mesma forma que na obra anterior, os colonos alemães precisam agir por conta própria para se defender do bando, pois não recebem a ajuda necessária do governo. Também no prefácio desse livro, Gerstäcker afirma que baseou a narrativa em fatos reais.

Segundo Bittner (2016), a escrita de Gerstäcker foi influenciada pelos ideais da Revolução Francesa e também pelos movimentos de libertação que reinavam na Alemanha naquela época. Dessa forma, ele se preocupava em trazer para suas obras diferentes pontos de vista e procurava apresentar as situações como as presenciara.

Suas narrativas trazem a aventura e o exotismo, mas ele não dissimula nem avilta. Na figura do índio Assowaum, em Justiceiros, ele ilustra a expulsão dos índios pelos brancos (processos semelhantes aparecem também em romances como Taiti e Abaixo do Equador) e não se esquiva de condenar a campanha de extermínio contra os povos nativos do continente americano (BITTNER, 2016, s.p. ī tradução nossa). ${ }^{8}$

Além dos romances, contos e diários de viagem publicados em sua maioria pela editora Costenoble, Gerstäcker escreveu regularmente, entre 1853 e 1872, para a revista Die Gartenlaube. ${ }^{9}$ Sua produção em Die Gartenlaube compreendia ensaios, contos curtos,

\footnotetext{
${ }^{7}$ Do alemão: ก̃Der größte Teil der Ereignisse ist keineswegs erdichtet, sondern hat sich, wenn auch auf verschiedenen Plätzen und in ausgedehnterem Zeitraum, wirklich zugetragen, besonders ist der Methodistenprediger eine geschichtliche Figurò. In: http://gutenberg.spiegel.de/buch/die-regulatoren-inarkansas-1602/2.

${ }^{8}$ Do alemão: ñEr erzählt Abenteuerliches, auch Exotisches, aber er beschönigt nicht und würdigt nicht herab. An der Person des Indianers Assowaum in den Regulatoren verdeutlicht er die Verdrängung der Roten durch die Weißen (ähnliche Gedanken finden sich zum Beispiel in den Romanen Tahiti oder Unter dem Äquator), und er scheut sich nicht, den Vernichtungsfeldzug gegen die Ureinwohner des amerikanischen Kontinents zu verurteilen.ò

${ }^{9}$ A revista Die Gartenlaube ï Illustriertes Familienblatt [Die Gartenlaube Ï Folha ilustrada para a família] foi uma das primeiras folhas ilustradas e a primeira grande revista de cunho popular de sucesso. Foi publicada pela
} 


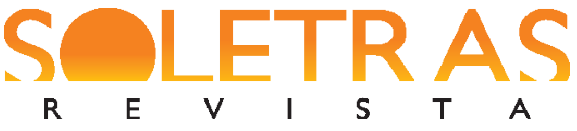

novelas e artigos direcionados, em grande parte, a possíveis emigrantes. Nesses artigos, Gerstäcker discutia possibilidades de imigração, vantagens e benefícios bem como armadilhas e perigos envolvidos nesse empreendimento. Em um desses artigos, publicado sob o título Deutsche Colonisation in Brasilien [Colonização alemã no Brasil] (1862), Gerstäcker expõe sua opinião acerca da emigração para o Brasil e apresenta também sua avaliação sobre as grandes diferenças regionais que vivenciou no país:

[e] stou firmemente convencido depois de, por um lado, ter conhecido esse país e, por outro, ter ouvido in loco o relato minucioso de pessoas que há muito se estabeleceram ali, de que o Brasil apresenta alguns aspectos bastante censuráveis e perigosos. Contudo, de um modo geral, o país oferece aos imigrantes alemães grandes vantagens. Eu pessoalmente, se tivesse a intenção de emigrar e me dedicar à agricultura, escolheria como destino a América do Sul e muito provavelmente me estabeleceria no sul do Brasil.

É importante notar, contudo, que Brasil é um termo muito amplo e indefinido, pois, enquanto a região norte desse vasto país é marcada por pântanos pestilentos, vegetação tropical e calor escaldante i e o alemão, como trabalhador livre, jamais poderia sobreviver lá entre plantadores e proprietários de escravos ī , o sul, ao contrário, oferece um clima magnífico e saudável, um solo rico e uma população consistente de compatriotas alemães que, com poucas exceções, encontram-se em boa situação (GERST ̈̈CKER, 1862, p. 243). ${ }^{10}$

Em outra edição da mesma revista, Gerstäcker publica um artigo intitulado Wohlgemeinte Warnung für Auswanderer [Aviso bem-intencionado para emigrantes] que, como sugere o título, tem o objetivo de alertar os emigrantes sobre os potenciais perigos a que estes poderiam estar sujeitos e, principalmente, alertá-los em relação aos agentes de emigração:

\begin{tabular}{llllllllll}
\hline primeira vez em 1853, em Leipzig, pela editora de & Ernst & Keil. Ver
\end{tabular} http://www.zeitschriften.ablit.de/periodika/pgrtlb.htm.

${ }^{10}$ Do alemão: ñMeiner j e $t z$ i g e $n$ Meinung nach, die ich mir gebildet, seitdem ich jenes Land theils selber kennen gelernt, theils an Ort und Stelle von Leuten die Jahre lang dort ansässig waren, viel und Ausführliches darüber gehört, bin ich der festen Ueberzeugung, daß Brasilien in seinen Verhältnissen wohl manches Tadelnswerthe und Gefährliche hat, im Ganzen aber dem deutschen Auswanderer auch große und gewichtige Vortheile bietet, und wenn ich selber auswandern und Ackerbau treiben wollte, so würde ich mir zum Ziel meiner Auswanderung $j$ e d e $n f$ a l l s Südamerika, aller Wahrscheinlichkeit nach das südliche Brasilien wählen.

Brasilien ist übrigens ein sehr weiter und unbestimmter Begriff, denn während der Norden des ungeheueren Landes seine pesthauchenden Sümpfe, seine allein tropische Vegetation und glühende Hitze hat, und der Deutsche dort $n$ i e unter den Pflanzern und Sclavenhaltern als freier Arbeiter existiren kann, bietet der Süden dagegen ein prachtvolles gesundes Klima, einen reichen Boden und eine dichte Bevölkerung deutscher Landsleute, die sich mit wenigen Ausnahmen Alle wohl befindenò. 
[...] o emigrante deve ir para onde bem entender. Peço-lhe apenas uma coisa: que, para seu próprio bem, tome cuidado com aquelas pessoas cujo interesse único é a própria emigração, embora assegurem repetidamente que este não é o caso: os agentes de emigração (GERST ÄCKER, 1862, s.p.)! $!^{11}$

Essa mesma visão que Gerstäcker explicita em seus artigos aparece também nas obras que escreveu tendo como pano de fundo a colonização alemã no Brasil. O romance $A$ Colônia. Cenas da vida no Brasil, publicado em 1862 na Alemanha, retrata a vida dos habitantes de Santa Clara, uma colônia fictícia localizada em Santa Catarina. A história é narrada por Könnern, um viajante alemão que pode ser visto como o alter ego de Friedrich Gerstäcker. Ao longo da obra, Könnern revela as alegrias e os infortúnios, as conquistas e os conflitos vivenciados pelos habitantes da pequena colônia. As longas descrições de Gerstäcker nos oferecem a oportunidade de acompanhar seu olhar sobre o Brasil daquela época, especialmente sobre o sul do país, e registram também as condições sociais, econômicas e políticas no Brasil em meados do século XIX.

Além disso, uma das mensagens principais de A Colônia é ressaltar que a emigração para o Brasil é uma excelente possibilidade para aqueles alemães que entendem de agricultura e de comércio e que não se esquivam do trabalho, mas é absolutamente desaconselhada aos aristocratas alemães, que sonhavam com a perspectiva de enriquecimento fácil no novo mundo e ao chegar decepcionavam-se, eram incapazes de se manter e acabavam se transformando em um pesadelo para os administradores das colônias, como vemos no seguinte trecho, no qual Sarno, o diretor da colônia de Santa Clara, relata a Könnern a saga do barão Jeorgy:

ñQuem era aquele?ò

ño Barão Jeorgy, descendente, segundo seu próprio relato, de uma família muito antiga e veio para cá com a ideia de se tornar um fazendeiro brasileiro. Ele assumiu uma colônia muito bem situada ï você deve ter passado por ela hoje pela manhãò.

ñAh, a casa lá em cima da colina, onde vive um encantador jovem casal de ascendência teuto-brasileira?

ñIsso mesmo, a chácara Köhler, como se chama agora ï e ele desperdiçou a propriedade em tempo tão inacreditavelmente curto que, ao fim, era

\footnotetext{
${ }^{11}$ Do alemão: $\tilde{n}[. .$.$] der Auswanderer mag gehen, wohin er eben Lust hat, aber nur um das Eine bitte ich ihn:$ seiner selbst wegen sich vor den Leuten besonders in Acht zu nehmen, die wirklich das einzige Interesse bei der Auswanderung selber haben, wenn sie auch immer und immer wieder versichern, daß es nicht der Fall wäre: den Auswanderungs-Agenten! Ò
} 
praticamente uma selva. Por fim, teve de vendê-la, pois já nem conseguia mais arcar com os custos e, naturalmente, o maior culpado disse era o diretor, já que este não queria lhe adiantar mais dinheiro. Desde então ele está com raiva de mim [...]ò (GERSTÄCKER, 2016, p. 42).

Outras questões, como a dificuldade de encontrar professores para as escolas e os conflitos religiosos entre os imigrantes protestantes e os brasileiros católicos são abordados nas obras de Gerstäcker e refletem episódios verídicos ocorridos nas colônias alemãs. Tanto a educação quanto a religião representam aspectos importantes na manutenção da cultura da terra de origem. Seyferth (1986, p. 61), por exemplo, aponta a associação entre igreja e escola nas colônias como suporte da ñconsciência étnicaò. Mesmo antes da nacionalização do ensino, que ocorrerá a partir de 1937, Gerstäcker já denuncia o descaso e o desrespeito do governo brasileiro em relação à manutenção dos costumes dos imigrantes. Em A Colônia, ele introduz, por exemplo, um acontecimento real que ficou conhecido nacionalmente como "A questão Kerth": a imigrante Margarida Kerth abandona o marido João Schopp em 1848 para viver com Franklin Brasileiro Jansen Lima. Em 1857, o então bispo, Dom Manuel do Monte Rodrigues de Araújo, anula o casamento protestante de Margarida Kerth, e João Schopp, alegando que este não estaria de acordo com as regras do Concílio de Trento. Margarida Kerth assume o credo católico e se casa com Franklin Brasileiro Jansen Lima (SANTIROCCHI, 2012, p. 89). Gerstäcker reproduz no livro o decreto emitido pelo bispo e em nota de rodapé informa: ño decreto acima é verdadeiro, apenas o sobrenome alemão foi modificado. Só muito recentemente os casamentos protestantes, através da nova lei matrimonial, foram declarados válidos também no Brasilò (GERSTÄCKER, 2016, p. 207).

Outra característica bastante relevante nas obras de Gerstäcker é a visão pormenorizada que ele apresenta de seus compatriotas: além do agricultor honesto e trabalhador, somos apresentados a tipos interesseiros, inescrupulosos, idealistas, ingênuos, saudosos, entre outros, comprovando claramente a heterogeneidade da imigração alemã no Brasil em sua obra. A profusão de personagens alemãs e a descrição minuciosa de Gerstäcker são elementos extremamente valiosos para estabelecermos contato com os imigrantes alemães do século XIX e, especialmente, para que tenhamos elementos para desmistificar a visão do imigrante alemão apenas como um tipo honesto e trabalhador. Como aponta Seyferth (2004), especialmente na segunda metade do século XIX, intensifica-se a noção de Deutschtum [germanidade] nas colônias brasileiras, tendo como um de seus pilares a difusão de um 


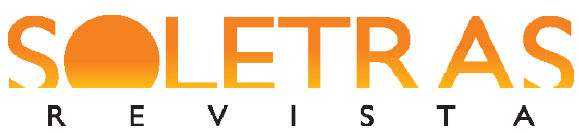

modelo germânico construído nos territórios colonizados $\bar{\imath}$ e, portanto, reinventado $\bar{\imath}$ com base nas ideias do Romantismo alemão. Esse modelo romântico preconizado pela Deutschtum i e cuja disseminação se dá prioritariamente através da literatura $i$ prioriza a figura do pioneiro corajoso e heroico e obviamente apaga as figuras que não se encaixam nele.

Ainda como resultado da passagem pela América do Sul e pelo Brasil, Gerstäcker publica um relato de viagem Achtzehn Monate in Südamerika [Dezoito meses na América do Sul] (1862) e alguns anos mais tarde, em 1869, Ein Parcerie-Vertrag. Erzählung zur Warnung und Belehrung für Auswanderer und ihre Freunde [Um contrato de parceria. Conto para advertência e instrução de emigrantes e seus acompanhantes], um conto no qual o autor denuncia a prática dos ñcontratos de parceriaò, ${ }^{12}$ alertando seus conterrâneos sobre os perigos de uma emigração precipitada: uma família alemã, persuadida por um inescrupuloso agente de emigração, assina um ñcontrato de parceriaò para, então, vir para o Brasil; eles chegam a Minas Gerais, onde são praticamente escravizados, destituídos de qualquer direito e sem ninguém que interceda a seu favor.

\section{Gerstäcker, o esquecido}

Existe esse Aleph no íntimo de uma pedra? Vi-o quando vi todas as coisas e o esqueci? Nossa mente é porosa para o esquecimento; eu mesmo estou falseando e perdendo, sob a trágica erosão dos anos, os traços de Beatriz. ${ }^{13}$

(Jorge Luis Borges)

Como lembra Borges acima, nossa mente é realmente porosa para o esquecimento. Embora atualmente poucos se lembrem de Friedrich Gerstäcker, ele foi um dos escritores mais bem-sucedidos do seu tempo e uma das primeiras celebridades literárias da Alemanha $\bar{~}$ seu rosto aparecia com tanta frequência na mídia impressa da época que ele era constantemente reconhecido na rua, mesmo que isso não lhe agradasse nem um pouco (GRETZSCHEL, 2016).

\footnotetext{
${ }^{12}$ Segundo Neumann \& Pavan (2016, p. 13), os contratos de parceria ñrepresentavam uma experiência negativa para muitos emigrados alemães, pois tratava-se de um contrato através do qual o emigrante recebia todos os custos da viagem pagos geralmente por um fazendeiro, para quem eles deveriam trabalhar até terem liquidado suas dívidas, o que na maioria das vezes se estendia por anos. Isso acabava levando muitas famílias ao desespero, pois a forma de trabalho era semelhante a dos escravos africanos que viviam nas fazendasò.

${ }^{13}$ Borges, Jorge Luis. ñO Alephò. In: Jorge Luis Borges: Obras Completas, v. I. São Paulo: Ed. Globo, 1998, p. 96.
} 


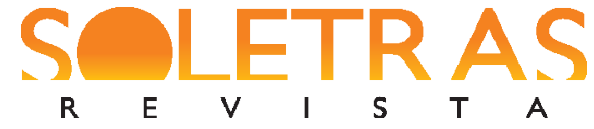

Concordamos com Bittner (2016), quando ele afirma que Gerstäcker foi um verdadeiro pioneiro da literatura de aventura, que suas obras são impactantes e cativam o leitor, que continuam atuais e que merecem ser lidas hoje tanto quanto foram no século XIX: "não é só o aspecto aventureiro nessas obras que prende o leitor, mas a densa atmosfera que remete à vida real que o autor $\bar{i}$ e isso também fica evidente $\bar{i}$ conhecia por experiência própria" (BITTNER, 2016, s. p, tradução nossa). ${ }^{14}$

Friedrich Gerstäcker é mencionado na importante obra do famoso Walter Benjamin, ñO narrador: considerações sobre a obra de Nikolai Leskovò ao tratar das narrativas e dos narradores. ñQuem viaja tem muito que contarò, ressalta Benjamin, e Friedrich Gerstäcker viajava muito para, a partir das viagens, poder contar suas histórias. Ainda sobre Gerstäcker, Benjamin afirma: ñCada uma delas [as famílias de narradores] conservou, no decorrer dos séculos, suas características próprias. Assim, entre os autores alemães modernos, Hebel e Gotthelf pertencem à primeira família, e Sielsfield e Gerstäcker à segundaò (BENJAMIN, 1977, p. 386).

Como explicar, então, seu esquecimento? Markum (2014) ressalta um traço importante, próprio não apenas de Gerstäcker, mas também de outros escritores daquele tempo:

Gerstäcker, assim como muitos viajantes da sua geração, não eram conhecidos por uma única carreira. Um ensaio não pode discutir Gerstäcker como romancista sem discutir suas declarações políticas. Não podemos falar sobre ele como um naturalista sem levar em conta suas observações antropológicas (MARKUM, 2014, s.p.). ${ }^{15}$

Essa característica se manifesta, então, na utilização de diversos gêneros textuais: contos, ensaios, romances, artigos ī nos quais se percebe que Gerstäcker não escrevia apenas para entreter um público determinado, mas para alertar, informar, refletir sobre o ser humano e seus caminhos, discutir posicionamentos políticos e condenar estratégias e comportamentos duvidosos, como vimos anteriormente nos excertos destacados de algumas de suas obras.

\footnotetext{
${ }^{14}$ Do alemão: ñNicht nur das Abenteuer fesselt in diesen Büchern, sondern darüber hinaus die sich mitteilende dichte Atmosphäre von Lebensbereichen, die der Autor ï auch das wird spürbar ï aus eigener Anschauung kannteò.

${ }^{15}$ Do inglês: ñGerstäcker, and many travelers of his generation, were not known for one career. An essay cannot discuss Gerstäcker as a novelist without discussing his political reporting. We cannot talk about him as a naturalist without noting his anthropological observations. Oे
} 


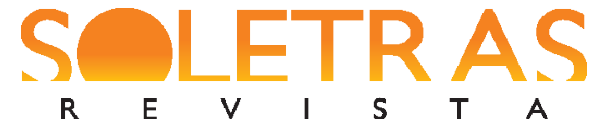

Bittner (2016) propõe ainda que talvez a dificuldade de catalogar a literatura de Gerstäcker seja um dos motivos do seu desaparecimento:

[t]alvez seu desaparecimento das livrarias possa ser explicado por suas obras situarem-se no âmbito de difícil categorização entre literatura adulta e literatura juvenil, por não serem simples e populares nem intelectuais e complexas, mas simplesmente empolgantes e, para os dias de hoje, às vezes até um pouco obstinadas e contraditórias (BITTNER, 2016, s.p. ī tradução nossa). ${ }^{16}$

Gerstäcker se interessava verdadeiramente pelos menos favorecidos e suas obras dão testemunho disso. Talvez não tenha se exposto o suficiente para que fosse lembrado, para que permanecesse na memória da história e da literatura, para que não naufragasse. Ele não escrevia para tornar-se famoso, segundo Bittner (2016), ele era um solitário e, quando estava na Alemanha, passava a maior parte do tempo recluso, trabalhando em seus manuscritos. Sua casa em Braunschweig ficava do outro lado do rio Oker e, na época, só era possível chegar até lá de barco.

Ele seguia seu próprio caminho, observava e analisava. Essa mesma postura se refletia em suas obras: permanecia nos bastidores, de onde fazia suas descobertas e revelações. [...] sua afeição pertencia às pessoas comuns, aos homens simples do interior, aos sem-terras, barqueiros, marinheiros, caçadores, nativos; pertencia também à natureza, na qual se sentia em casa (BITTNER, 2016, s.p. ī tradução nossa). ${ }^{17}$

Muzart (1995, p. 88) adverte que ñum solitário é sempre um ser meio à margem, secreto, diferente, perigoso...ò. Convém lembrar que poucas décadas antes do nascimento de Gerstäcker, ainda havia perseguição às bruxas $\bar{\imath}$ o último processo contra uma f̂́bruxaò na Alemanha ocorreu em 1775 e Gerstäcker nasceu em 1816 ì e, segundo Blazek (2011), a

\footnotetext{
${ }^{16}$ Do alemão: ñVielleicht ist seine Verdrängung aus den Buchhandlungen damit zu erklären, dass seine Werke in jenem schwer katalogisierbaren Bereich zwischen Erwachsenenliteratur und Jugendbuch angesiedelt sind, dass sie weder glatt und populär noch intellektuell und verschlüsselt sind, sondern ganz einfach spannend lesbar und manchmal auch ein bisschen widerborstig und widersprüchlich für uns heute. Ò

${ }^{17}$ Do alemão: ñEr ging seiner eigenen Wege, beobachtete und analysierte. Diese Haltung spiegelt sich in seiner Literatur wider: Er schaut hinter die Kulissen, deckt auf und entlarvt. [...] Seine Sympathie gehört den Ăeinfachen Leutenñ, den Backwoodsmen, Squatters, Flussschiffern, Matrosen, Jägern, Eingeborenen, sie gehört der Natur, in der er sich heimisch fühlte. Ò
} 


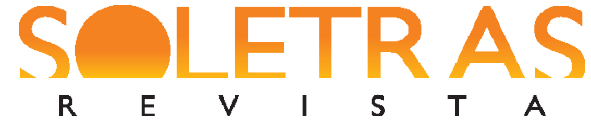

DOSSIÊ ï N. 34 ï 2017.2 ï CLAUDIA FERNHANDA PAVAN E GERSON ROBERTO NEUMANN

punição para crimes graves através da roda do despedaçamento foi utilizada pela última vez em 1841 na Prússia. ${ }^{18}$ Ser diferente e secreto naquele tempo podia ser realmente perigoso.

Nesse mesmo artigo, Muzart ressalta a importância da vida social e das relações com o poder estabelecidas por aqueles escritores oitocentistas que, no contexto brasileiro, não foram esquecidos. Essa era uma dinâmica igualmente presente no meio literário alemão daquele período e não são poucos os autores que mencionam o incômodo que Gerstäcker sentia em relação à vida pública. Käther (2012) é outro autor que sublinha a preferência de Gerstäcker por uma vida longe dos holofotes, sem grandes biografias, sem lobby.

Talvez esses fatores tenham colaborado para o esquecimento de Gerstäcker e de suas obras. Ao contrário, por exemplo, de Karl May que, apesar das acusações de ter plagiado o trabalho de Gerstäcker, continua sendo lembrado, republicado, refilmado e, especialmente, celebrado, como aponta Käther (2012) ao lembrar a aproximação do aniversário de 100 anos da morte de May: ñ[...] seremos novamente bombardeados: a imprensa deve espalhar artigos bajuladores e as biografias de May já estão expostas nas livrariasò (KÄTHER, 2012, s. p, tradução nossa). ${ }^{19}$

No Brasil, o esquecimento de Gerstäcker representa uma grande perda: como já apontamos anteriormente, as obras de Gerstäcker, que têm o território brasileiro como pano de fundo, não apenas nos trazem descrições detalhadas do país e dos acontecimentos daquela época, como também nos oferecem abundantes referências acerca dos alemães que vieram colonizar o Brasil. Temos em suas obras uma visão dos alemães e seus descendentes distinta daquela apresentada por autores teuto-brasileiros do século XIX, empenhados na criação e difusão da noção de Deutschtum; uma visão, portanto, mais sóbria e menos romantizada.

Também é importante refletir sobre a tradução das obras de Gerstäcker, levando em conta que a tradução representa uma das formas mais frequentes de acesso a diferentes culturas e a diferentes concepções de mundo, de ideias e de práticas. Segundo Moser (2015), nos Estados Unidos e na Inglaterra, apenas 3\% das publicações são traduções. Assim, seria mais fácil compreender que Gerstäcker não tivesse sido traduzido para o inglês. Contudo,

\footnotetext{
${ }^{18}$ A roda do despedaçamento era um instrumento de tortura e execução. O condenado era preso à roda e tinha seus ossos quebrados a marteladas, sendo que o objetivo inicial da ação era a mutilação dolorosa do corpo antes da morte. In: https://de.wikipedia.org/wiki/R\%C3\%A4dern\#cite_note-2.

${ }^{19}$ Do alemão: $\tilde{\mathrm{n}}[. .$.$] da werden wir wieder einiges zu hören bekommen, die Presse wird lobhudelnde Feuilletons$ ausschwitzen. Die May-Biographien in den Buchläden stehen schon bereitò.
} 


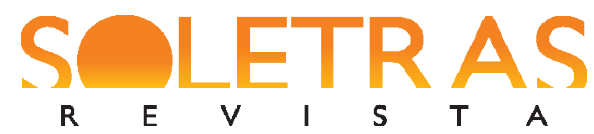

muitas das obras que ele escreveu e que tinham como pano de fundo os Estados Unidos e outros lugares em que o idioma é a língua inglesa, como a Austrália, foram traduzidas para o inglês ainda no século XIX. Seu primeiro livro ī Streif- und Jagdzüge durch die Vereinigten Staaten Nordamerikas $\bar{\imath}$ aquele baseado nas cartas que escreveu para a mãe, publicado originalmente em 1843 i foi traduzido para o inglês sob o título Wild sports in the far West em 1856 e Die Regulatoren in Arkansas, publicado na Alemanha em 1846, foi traduzido para o inglês em 1857 sob o título Regulators of Arkansas. Blamires (2009, p. 312) lista ainda tem várias outras obras de Gerstäcker que foram traduzidas e publicadas em inglês ao longo do século XIX. ${ }^{20}$

No que se refere ao mercado de traduções no Brasil, Feres \& Brisolara (2016) declaram que aproximadamente $60 \%$ das publicações brasileiras são traduções. É no mínimo curioso, portanto, que haja apenas uma obra de Gerstäcker traduzida e publicada em português ì o que aconteceu somente em 2016: Die Colonie. Brasilianisches Lebensbild [A Colônia ī Cenas da vida no Brasil] que, como já apontamos, foi originalmente publicada na Alemanha em 1862.

Apesar do sucesso que teve no século XIX, Gerstäcker, hoje, é um escritor praticamente desconhecido. Até mesmo o museu em Braunschweig que leva seu nome foi fechado em 2016 i ano do aniversário de 200 anos do nascimento do escritor ī não obstante os esforços de Thomas Ostwald, fundador e administrador do museu:

[p]or anos procurei por uma solução para manter o museu. Todas as possíveis propostas foram rejeitadas, embora o museu possuísse, além de uma coleção original de objetos etnológicos $\bar{I}$ muitos do próprio Friedrich Gerstäcker $\bar{\imath}$, uma extensa coleção de armas da época dos pioneiros. Também uma exposição, sem precedentes em Braunschweig sobre a "emigração do ducado de Braunschweig desde o século XVIII (!) não foi considerada pelas autoridades digna de preservação. [...] Fica um sabor amargo na boca e a pergunta aos responsáveis: por quê? Por que um montante de mais de 10.000 euros é destinado a um festival regional

\footnotetext{
${ }^{20}$ Segundo Blamires (2009, p. 312), Der Deutschen Auswanderer Fahrten und Schicksale (1847) foi traduzido por D. Black sob o título The Wanderings and Fortunes of some German Emigrants (London: D. Bogue, 1848) e Die Flußpiraten des Mississippi (1848) foi traduzido como The Pirates of the Mississippi (London, 1856). Gold! Ein Californisches Lebensbild aus dem Jahre 1849 (1858) foi traduzido e publicado um ano mais tarde como Each for Himself; or, the Two Adventurers (London, 1859) e Der kleine Goldgräber in Californien (1858), traduzido como The Young Gold-Digger ou a Boyôs Adventures in the Gold Regions foi publicado em 1860.
} 


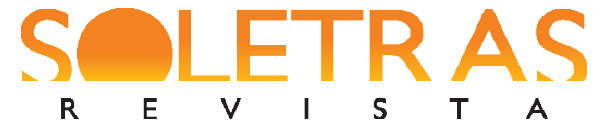

DOSSIÊ ï N. 34 ï 2017.2 ï CLAUDIA FERNHANDA PAVAN E GERSON ROBERTO NEUMANN

enquanto um museu literário sem fins lucrativos é simplesmente fechado? (OTSWALD, 2016, s.p. $\bar{~}$ tradução nossa). ${ }^{21}$

Depois de 34 anos em funcionamento, o museu agora se reduz a uma página na internet na qual é possível ainda fazer um passeio virtual pelo local. ${ }^{22}$

Friedrich Gerstäcker morreu aos 56 anos em 31 de maio de 1872, em Braunschweig, em consequência de um acidente vascular cerebral, quando se preparava para mais uma grande viagem, dessa vez para a Ásia.

\section{Considerações finais}

Procuramos, no presente trabalho, mostrar a relevância de Friedrich Gerstäcker no cenário literário internacional, destacando sua importância, sobretudo, para o polissistema literário brasileiro. Além disso, sugerimos algumas hipóteses para seu apagamento do contexto literário internacional $\bar{i}$ inclusive na própria Alemanha $\bar{\imath}$, como os impasses relacionados à categorização da sua obra ou sua referida falta de interesse em se autopromover. Embora a vida social de Gerstäcker não deva ser parâmetro para o valor estético e textual do seu trabalho, é, como aponta Muzart (1995), um fator que desempenha um importante papel na dinâmica de canonização dos escritores em geral.

Acreditamos que o esquecimento de Gerstäcker representa, especialmente no Brasil, uma grande perda, pois o leitor é privado de sua escrita detalhada, que denota uma visão atenta e refletida, própria do seu espírito investigativo e questionador. Através de suas muitas viagens, Gerstäcker ampliou sua percepção acerca do comportamento humano, principalmente, no que diz respeito às questões relacionadas à emigração alemã para o novo mundo. Em função da influência que movimentos como a Revolução Francesa exerceram sobre sua escrita e do seu interesse em reunir informações que fossem proveitosas para seus

\footnotetext{
${ }^{21}$ Do alemão: $\tilde{\mathbf{n}}$ ch habe über Jahre nach einer Lösung für eine gesicherte Nachfolge gesucht. Alle Vorschläge für eine vernünftige Bestandssicherung wurden abgelehnt, obwohl das Museum nicht nur eine einmalige Sammlung von ethnologischen Gegenständen, teilweise aus dem Nachlass Friedrich Gerstäckers, besaß. Auch eine umfangreiche Waffensammlung der Pionierzeit sowie eine bislang in Braunschweig einmalige Ausstellung zum Thema ĂAuswanderung aus dem Herzogtum Braunschweig seit dem 18. Jahrhundert (!)ñ wurden nicht als erhaltenswert von den Verantwortlichen eingestuft. [...]Es bleibt ein bitterer Nachgeschmack und die Frage an die Verantwortlichen: Warum? Wieso wird einem Stadtteilfest ein Betrag von mehr als 10.000 Euro für eine Veranstaltung zugesagt, und ein nicht kommerziell betriebenes Museum einer literarischen Gesellschaft wird einfach geschlossen?⿳亠े冖

${ }_{22} \mathrm{O}$ passeio virtual pelo Museu Friedrich Gerstäcker está disponível em: http://thomasregnat.de/gerstaecker/0101.html.
} 


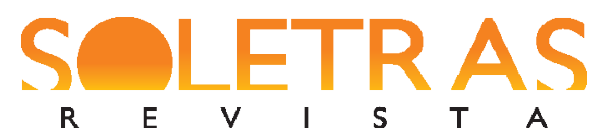

conterrâneos na busca por um novo lar, suas obras apresentam pontos de vista variados, instigando uma leitura crítica e sempre atual.

Resgatar a figura e as obras de Friedrich Gerstäcker representa certamente um enriquecimento para o polissistema literário brasileiro, uma expansão para além dos textos canônicos. Esse resgate nos oferece ainda a oportunidade de aprimorar conhecimentos histórico-literários em relação a importantes eventos ocorridos no século XIX e de expandir nossa perspectiva em relação à imigração alemã e aos próprios imigrantes.

\section{Referências}

ALEXANDER, Ian. Formação nacional e cânone ocidental: literatura e tradição no novo mundo. 294 f. Tese (doutorado em Literatura Comparada). Porto Alegre: Universidade Federal do Rio Grande do Sul, 2010. Disponível em: <http://www.lume.ufrgs.br/handle/10183/27944>. Acesso em: 09 ago. 2017.

ALMEIDA, Rogério C. Grotesco: entre o canônico e o marginal. In: Revista Estação Literária, Londrina, v. 12, p. 206-216, jan. 2014. Disponível em: <http://www.uel.br/pos/letras/EL/vagao/EL12-Art12.pdf>. Acesso em 09 ago. 2017.

ANDERSON, Benedict. Comunidades Imaginadas: reflexões sobre a origem e a difusão do nacionalismo. Trad. Denise Bottman. São Paulo: Companhia das Letras, 2013.

BENJAMIN, Walter. Der Erzähler. In: Illuminationen. Ausgewählte Schriften 1. Frankfurt am Main: Suhrkamp, 1977, S. 385-410.

BITTNER, Wolfgang. Friedrich Gerstäcker ï spannend, widerborstig und widersprüchlich. In: Hintergrund. Das Nachrichtenmagazin, 2016. Disponível em: $<$ https://www.hintergrund.de/feuilleton/literatur/friedrich-gerstaecker-spannend-widerborstigund-widerspruechlich/>. Acesso em: 10 ago. 2017.

BLAMIRES, David. Telling Tales. The impact of Germany on English children's books. Cambridge: Open Book Publishers, 2009. Disponível em: <http://books.openedition.org/obp/617?lang=de>. Acesso em: 18 ago. 2017.

BLAZEK, Matthias. Das letzte Mal wurde die Strafe des Räderns in Preußen 1841 angewandt. In: Preußische Mitteilungen, n. 202, Ago. 2011. Disponível em: <https://de.wikipedia.org/wiki/R\%C3\%A4dern\#cite_note-2>. Acesso em: 13 ago. 2017.

BLOOM, Harold. O cânone ocidental. Trad. Marcos Santarrita. Rio de Janeiro: Objetiva, 1995.

BONNICI, Thomas. Teoria e crítica literária feminista: conceitos e tendências. Maringá, PR: Eduem, 2007. 


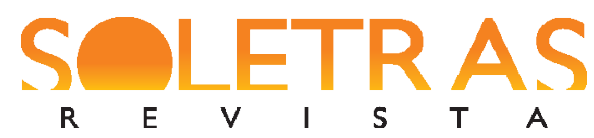

CORRÊA, Alamir Aquino. Historiografia, cânone e autoridade. In: Anais do Congresso de estudos linguísticos e literários do Paraná ī CELLIP. Umuarama: Unipar, 1995.

COUTINHO, Eduardo. Literatura comparada, literaturas nacionais e o questionamento do cânone, Revista brasileira de literatura comparada, Rio de Janeiro: Abralic, n. 3, 1996.

FERES, Lilia Baranski; BRISOLARA, Valéria Silveira. A literatura brasileira em tradução: o caso do Programa de Apoio à Tradução e à Publicação de Autores Brasileiros no Exterior. In: Letrônica. Revista Digital do Programa de Pós-Graduação em Letras da PUCRS. Porto Alegre, v. 09, n. esp. (supl.), p. 144-154, nov. 2016. Disponível em: <http://revistaseletronicas.pucrs.br/ojs/index.php/letronica/article/view/22388>. Acesso em: 15 Ago. 2017.

GERSTÄCKER, Friedrich. Deutsche Colonisation in Brasilien. In: Die Gartenlaube. Leipzig: Ernst Keil, n. 29, p. 454 - 456, 1862.

Wohlgemeinte Warnung für Auswanderer. In: Die Gartenlaube. Leipzig: Ernst Keil, 1862, Nr. 30, p. 479 - 480.

A Colônia. Cenas da Vida no Brasil. Porto Alegre: Gradiva Editorial, 2016.

Die Colonie. Brasilianisches Lebensbild. Leipzig: Hermann Constanoble, 1862. Disponível em: <http://gutenberg.spiegel.de/buch/die-colonie-6539/1>. Acesso em: 05 Ago. 2017.

Die Flußpiraten des Mississippi. Leipzig: Hermann Constanoble, 1848. Disponível em: <http://gutenberg.spiegel.de/buch/die-flusspiraten-des-mississippi-5581/2>. Acesso em 05 Ago. 2017.

Die Regulatoren in Arkansas. Leipzig: Hermann Constanoble, 1846. Disponível em: $<$ http://gutenberg.spiegel.de/buch/die-regulatoren-in-arkansas-1602/2>. Acesso em 05 Ago. 2017.

GRABBE, Hans-Jürgen. Weary of Germany ï Weary of America. In: BARCLAY, David E.; GLASER-SCHMIDT Elisabeth. Transatlantic Images and Perceptions: Germany and America Since 1776. Cambridge University Press, 1997. Disponível em: <https://books.google.com.br/books?id=aK_FZzejQGQC\&pg=PA69\&lpg=PA69\&dq=\%22W eary+of+Germany+-+Weary+of+America\%22\&source $=$ bl\&ots $=$ eK-

BJee8jg\&sig=X8puUWNfmUHqodzfy2nSRhfgH4E\&hl=de\&sa=X\&ved=0ahUKEwi5_TA7-

LVAhVEEJAKHe1fBUEQ6AEISjAI\#v=onepage\&q=\%22 Weary\%20of\%20Germany\%20\%20Weary\%20of\%20America\%22\&f=false>. Acesso em 12 Ago. 2017.

GRETZSCHEL, Matthias. ñDer Hamburger, von dem Karl May abschriebò. In: Hamburger Abendblatt, 2016.

Disponível em: 


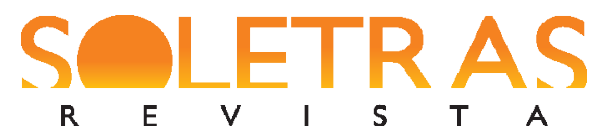

DOSSIÊ ï N. 34 ï 2017.2 ï CLAUDIA FERNHANDA PAVAN E GERSON ROBERTO NEUMANN

<https://www.abendblatt.de/vermischtes/journal/thema/article207551695/Der-Hamburgervon-dem-Karl-May-abschrieb.html>. Acesso em 10 ago. 2017.

HÜHNERFELD, Paul. Der Ehrenbürger von Arkansas. In: Zeit Online, 2012/1957. Disponível em: <http://www.zeit.de/1957/20/der-ehrenbuerger-von-arkansas>. Acesso em: 12 ago. 2017.

KÄTHER, Matthias. Der vergewaltigter Klassiker. In: Das Blättchen - Zeitschrift für Politik, Kunst und Wirtschaft, 2012. Disponível em: <http://das-blaettchen.de/2012/03/dervergewaltigte-klassiker-10313.html>. Acesso em: 15 ago. 2017.

MARKUM, Leah. The little-known history of Friedrich Gerstäcker. In: Research Frontiers, 2014. Disponível em: <https://researchfrontiers.uark.edu/the-little-known-history-of-friedrichgerstacker/>. Acesso em 10 ago. 2017.

MOSER, Benjamin. Trazer escritores estrangeiros para domínio do inglês enriquece a literatura. In: Uol Notícias, 2015. Disponível em: $<$ https://noticias.uol.com.br/midiaglobal/nytimes/2015/07/11/trazer-escritores-estrangeirospara-dominio-do-ingles-enriquece-a-literatura.htm>. Acesso em: 18 ago. 2017.

MUZART, Zahidé Lupinacci. A questão do cânone. In: Rev. Anuário de Literatura. Florianópolis: Universidade Federal de Santa Catarina, n. 3, 1995. Disponível em: <https://periodicos.ufsc.br/index.php/literatura/article/view/5277>. Acesso em: 15 ago. 2017.

NEUMANN, Gerson Roberto; PAVAN, Cláudia Fernanda. A leitura do Brasil do século XIX a partir da perspectiva literária na obra de Friedrich Gerstäcker. In: Anais do XI SIHL Seminário Internacional de História da Literatura, 2015. Disponível em: <http://ebooks.pucrs.br/edipucrs/anais/sihl/assets/2015/30.pdf>. Acesso em: 16. Ago. 2017.

NEUMANN, Gerson Roberto; PAVAN, Cláudia Fernanda. Friedrich Gerstäcker. Um escritor alemão do século XIX, sua passagem pelo Brasil e obras resultantes deste contato. In: GERSTÄCKER, Friedrich. A Colônia. Cenas da Vida no Brasil. Porto Alegre: Gradiva Editorial, 2016.

NEUNFELD, Beatriz H. A história oral na escola: memórias e esquecimentos na cultura do povo tradicional pomerano e no ensino de história em São Lourenço do Sul/RS. 109 F. Dissertação (mestrado profissional em História). Rio Grande: Universidade Federal do Rio Grande, 2016.2 Disponível em: <http://www.poshistoria.furg.br/images/stories/dissertacoes/tcm\%20defesa\%20final\%20beatr iz.pdf>. Acesso em: 10 Ago. 2017.

OSTWALD, Thomas. Thomas Ostwald: Ein rabenschwarzer Tag für Braunschweig. In: Regionalwolfenbüttel.de, 2016. Disponível em: <http://regionalwolfenbuettel.de/thomasostwald-ein-rabenschwarzer-tag-fuer-braunschweig/>. Acesso em 19 Ago. 2017. 


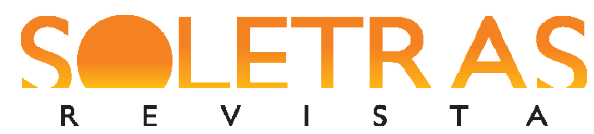

DOSSIÊ ï N. 34 ï 2017.2 ï CLAUDIA FERNHANDA PAVAN E GERSON ROBERTO NEUMANN

PAUSCH, H. A. ñVergesseneò Autoren bei Arno Schmidt: Das Beispiel Johann Carl Wezel. In: Knapp, G. P. Autoren damals und heute. Literaturgeschichtliche Beispiele veränderter Wirkungshorizonte (Amsterdamer Beiträge Zur Neueren Germanistik), 1991.

PERRONE-MOISÉS, Leyla. Altas literaturas. São Paulo: Companhia das Letras, 1998.

SANTIROCCHI, Ítalo Domingos. O matrimônio no império do Brasil: uma questão de Estadoò. In: Revista Brasileira de História das Religiões. ANPUH, Ano IV, n. 12, 2012. Disponível em: <http://www.dhi.uem.br/gtreligiao/pdf11/04.pdf>. Acesso em: 15 Ago. 2017.

SEYFERTH, Giralda. Imigração, colonização e identidade étnica (notas sobre a emergência da etnicidade em grupos de origem europeia no sul do Brasil). In: Revista de Antropologia, v. 29, 1986. Disponível em: <https://www.revistas.usp.br/ra/article/view/111143/109450>. Acesso em: 09 ago. 2017.

SEYFERTH, Giralda. A ideia de cultura teuto-brasileira: literatura, identidade e os significados da etnicidade. In: Horizontes Antropológicos, v. 10, n. 22, jul.-dez., 2004. Disponível em: < http://www.scielo.br/scielo.php?script=sci_arttext\&pid=S010471832004000200007>. Acesso em: 09 ago. 2017.

TRESPACH, Rodrigo. Alemães para toda obra. In: Revista de História Biblioteca Nacional, ano 9, n. 102, 2014. Disponível em: <https://angelinawittmann.blogspot.com.br/2014/12/artigo-da-revista-de-historia.html>. Acesso em: 10 ago. 2017.

\section{Requiem for Gerstäcker, the restless lonesome}

ABSTRACT: Friedrich Gerstäcker was a German traveler and writer. He was born in Hamburg in 1816 and dedicated his life to exploring the colonies of the new world, writing several works which focused on the German immigration during the nineteenth century and on the consequences of this movement for the German people. Before beginning his career as a writer, Gerstäcker traveled through the Americas and through many other countries, had a closer look into the lives of immigrants and saw in his writing a way to disseminate information about all issues involved in the immigration process. His collected writings include over forty volumes; regarding the German immigration in Brazil, he wrote three books $\bar{i}$ all published in Germany in the sixties of the nineteenth century. However, only very recently one of these works has been translated into Portuguese and published in Brazil. In this paper, we intend to highlight the importance of this author within the Brazilian literary polysystem and discuss the reasons and possible consequences of his forgetting.

Keywords: Friedrich Gerstäcker. Migration in the nineteenth century. Translated literature.

Recebido em: 29 de agosto de 2017.

Aprovado em: 08 de outubro de 2017. 